NBER WORKING PAPER SERIES

\title{
MACROECONOMIC ADJUSTMENT WTTH SEGMENTED LABOR MARKETS
}

\author{
Pierre-Richard Agénor \\ Joshua Aizenman
}

Working Paper No. 4769

\section{NATIONAL BUREAU OF ECONOMIC RESEARCH \\ 1050 Massachusetts Avenue \\ Cambridge, MA 02138 \\ June 1994}

We would like to thank, without implications, Donald J. Mathieson and Dennis Snower for helpful discussions and comments on a preliminary version. This paper is part of NBER's research program in International Trade and Investment. Any opinions expressed are those of the authors and not those of the International Monetary Fund or of the National Bureau of
Economic Research. 


\title{
MACROECONOMIC ADJUSTMENT WITH SEGMENTED LABOR MARKETS
}

\begin{abstract}
This paper analyzes the macroeconomic effects of fiscal and labor market policies in a small open developing country. The basic framework considers an economy with a large informal production sector and a heterogeneous work force. The labor market is segmented as a result of efficiency considerations and minimum wage laws. The basic model is then extended to account for unemployment benefits, income taxation, and imperfect labor mobility across sectors.

Under the assumption of perfect labor mobility, we show that a permanent reduction in government spending on nontraded goods leads in the long run to a depreciation of the real exchange rate, a fall in the market-clearing wage for unskilled labor, an increase in output of traded goods, and a lower stock of net foreign assets. A permanent reduction in the minimum wage for unskilled workers improves competitiveness, and expands the formal sector at the expense of the informal sector. Hence, in a two-sector economy in which the minimum wage is enforced only in the formal sector and wages in one segment of the labor market are competitively determined, efficiency wage considerations do not alter the standard neoclassical presumption. A reduction in unemployment benefits is also shown to have a positive effect on output of tradable goods by lowering both the level of efficiency wages and the employment rent of skilled workers.
\end{abstract}

Pierre-Richard Agénor Research Department International Monetary Fund Washington, D.C. 20431
Joshua Aizenman

Department of Economics

Dartmouth College Hanover, NH 03755 and NBER 


\section{Introduction}

Studies of urban labor markets in developing countries have come to distinguish between the formal and informal sectors on the basis of whether employment relationships are subject or not to various labor market regulations and other institutional constraints. ' In the formal sector, which consists of medium-and large-scale enterprises, workers are entitled to a variety of benefits, such as minimum standards for working conditions, job security provisions, social security and disability protection, pension plans, and health insurance. Skilled and unskilled workers are hired through formal contracts, with labor unions (or collective bargaining mechanisms) playing in some countries an important role in the determination of wages. The degree of compliance with minimum wage laws may vary considerably across production sectors. By contrast, in the informal segment of the urban labor market--which includes self-employed individuals and small privately-owned enterprises producing mainly services and other nontradables--labor regulations are usually not enforced. Activities in this sector rely mostly on the direct provision of labor services by owners and their families. Paid labor is used (usually without any formal employment contract) only occasionally. Although the informal labor market is characterized by free entry, job insecurity is pervasive, wages are highly flexible, and workers get very few benefits from their employers. Minimum wage laws do not apply or are not consistently enforced, and collective bargaining plays a limited role in the determination of wages.

By most accounts, the informal sector represents a sizable

${ }^{1}$ See, for instance, Mazumdar (1983) and Turnham (1993). Rural labor markets, which account for a substantial component of employment in many developing countrles, are characterized by a large share of self-employed persons and unpaid family workers. Wage earners bound by explicit contracts are also employed in agriculture, but is a less
common occurence. 
proportion--between 30 and 60 percent--of economic activity and total employment in developing countries, particularly in some parts of Asia, the Middle East, and Sub-Saharan Africa. ${ }^{2}$ A consequence of the formal-informal dualism induced by the lack of enforcement of government legislation is the segmentation of the urban labor market, which plays a crucial role in explanations of urban poverty, unemployment and underemployment in developing countries. Labor market segmentation can be defined as a situation where, because of barriers--institutional or otherwise--to occupational mobllity between sectors, a worker in the "low-wage" sector does not have full access to a job in the "high-wage" sector held by an observationally identical worker (Taubman and Wachter, 1986). If there were no barriers, workers in the low-wage sector would enter the high-wage sector and bid wages down unt1l earnings across sectors were equalized. More succintly, labor market segmentation implies persistent wage differentials for observationally identical workers.

The best-known model of labor market segmentation in developing countries was developed by harris and Todaro (1970), in their attempt to explain the persistence of migration from rural to urban areas, despite the existence of widespread urban unemployment. A key feature of the model is the equality of expected (rather than actual) wages in the urban sector and the rural areas as the basic equilibrium condition of the labor market. Harris and Todaro showed that the existence of a binding minimum wage in the urban sector leads, even if the rural labor market is competitive, to a persistent wage differential between the rural and urban sectors and to the emergence of urban unemployment.

In the Harris-Todaro framework, as in many models of labor market adjustment, labor is homogeneous and perfectly mobile across sectors.

${ }^{2}$ See Rosenzweig (1988) and Turnham (1993). Empirical estimates usually measure employement in the informal sector as the sum of selfemployed workers, unpald family workers, and domestic workers. Existing data must, however, be interpreted with care. 
Labor market segmentation emerges as a result of the government imposing a minimum wage in urban areas. However, an important feature of urban labor markets in developing countries--and, indeed, of labor markets everywhere--is the observation that workers are endowed with different skills, and may face short-term constraints on mobility across sectors as well as across different skill categories. In addition, wage differentials may emerge not only as a result of institutional constraints but also as a consequence of firms. wage-setting decisions aimed at enhancing productivity of a given category of workers. Labor force heterogeneity, imperfect sectoral mobility, and productivity considerations add new dimensions to the analysis of labor market segmentation. In particular, they provide important elements for examining potential spillover effects across different segments of the labor market, and the behavior of sectoral wages. Accounting for these features has important implications for understanding the effects of macroeconomic and structural policy shocks in developing countries.

The purpose of this paper is to analyze the effects of fical and labor market policies on output, wages, and unemployment in a dynamic, general equilibrium model of a small open developing economy with a large informal sector and segmented labor markets. Our analysis is based on the prevalent view among development economists that the absence-or lack of enforcement--of government regulations is the defining characteristic of the informal sector. Section II develops the basic framework, which distinguishes between skilled and unskilled labor and assumes perfect mobility across sectors, and examines the effect of changes in government expenditure and the minimum wage paid to unskilled workers on the composition of employment. Section III introduces income taxation and unemployment benefits, and analyzes how these modifications affect the determination of equilibrium wages,

${ }^{3}$ The Implications of labor market segmentation in the absence of worker heterogeneity have been examined by Agénor and Santaella (1993) and Demekas (1990) in a short-term macroeconomic context, and by Edwards (1988) in the context of trade and structural reforms. 
productivity, and employment. Section IV extends further the basic framework to consider the case where mobility of unskilled workers between the formal and informal sectors is imperfect. Finally, Section $V$ summarizes the main implications of the paper and discusses some possible extensions of the analysis.

\section{A Basic Framework}

Consider a small open economy in which there are three types of agents: producers, households, and the government. The economy consists of two sectors: a formal sector, which produces a traded good using skilled and unskilled labor, and the informal sector, which produces a nontraded good, using only unskilled labor." The relative price of the traded good is determined by the equilibrium condition of the nontraded good market.

The capital stock in each sector and the composition of the labor force between skilled and unskilled workers are assumed fixed during the time frame of the analysis. Skilled and unskilled labor are perfect substitutes in the production of the nontraded good in the informal sector. Workers are assumed initially perfectly mobile across sectors. A mininum wage for unskilled labor imposed by government fiat exists, but is enforced only in the formal sector. The wage rate for skilled labor in the formal sector is assumed set on the basis of efficiency considerations (taking into account workers' opportunity earnings), leading to an above-equilibrium wage. ${ }^{5}$ By contrast, wages of unskilled workers in the informal sector are fully

Assuming that the formal sector produces also a nontraded good would complicate the analysis without yielding additional insight.

SThere is by now a voluminous ilterature in developed countries that views involuntary unemployment as the result of efficiency wages. See Weiss (1990) and, for a more critical view, Carmichael (1990). shocks in a two-sector model examine the impact of macroeconomic policy and relative wage rigidity induced by efficiency considerations 
flexible. Once employment decisions for both categories of labor skills are taken by producers in the formal sector, the informal sector absorbs all workers that are not hired in the formal sector. since all skilled workers that are unable to find a job in the formal sector are willing to work as unskilled labor in the production of the nontraded good in the informal sector, unemployment cannot emerge-. although labor may be inefficiently allocated. Equilibrium of the labor market in the informal sector obtains once total supply and demand are equalized through wage adjustment.

Households consume both traded and nontraded goods produced in the formal and informal sectors, supply labor inelastically and hold a traded bond, which bears a real rate of return determined on world markets. Domestic agents can borrow and lend freely at that rate, which varies inversely with the economy's stock of bonds as well as the composition of domestic output. The government consumes traded and nontraded goods, and finances its expenditure by varying lump-sum taxes on households. Finally, wage and employment expectations--which affect, as discussed in section IV, the decision to migrate across sectors--are assumed to depend on prevailing conditions in the labor market.

1. Production, effort, and the labor market

The production technology in the formal sector is given by ${ }^{7}$

$$
Q_{F}-Q_{F}\left(e L_{S}, L_{F U}\right)
$$

\footnotetext{
The dichotomy in wage formation can be justified by assuming that efficiency considerations result from firms' desire to avert shirking (as discussed below) and minimize the cost of monitoring workers' effort. Assume also, as argued in the introduction, that the formal sector consists essentially of "large" firms, while the informal sector consists only of "small" firms. A plausible conjecture is therefore that small firms can monitor nearly costlessly the level of effort produced by their workers, thus obviating the need to pay efficiency wages.

For convenience, time subscripts are omitted in what follows. Except otherwise Indicated, the total derivative of a function of a single argument is denoted by a prime.
} 
where $Q_{F}$ denotes output, $e$ the level of effort per skilled worker (which is bounded between 0 and unity by an appropriate choice of units), $L_{S}$ employment of skilled workers and $L_{F U}$ employment of unskilled workers, both measured in natural units. Production takes place under decreasing returns to both categories of labor, which are assumed to be imperfectly substitutable. Setting the world price of traded goods to unity, the domestic price of output of the formal sector is equal to the nominal exchange rate, $\bar{E}$, which is assumed fixed in what follows.

The first step in the analysis of production decisions is to determine the level of effort that firms in the formal sector will demand from skilled workers. Assume that consumption and effort decisiuns are separable, and that the decision to provide effort depends only on the wage earned $\omega$ and the disutility of effort. All workers share the same instantaneous utility function $u(\omega, e)$ which, after appropriate normalizations, is defined as $\ln \left[\omega^{\gamma}(1-e)^{1-\gamma}\right]$, where $0<\gamma<1$. Let $\pi$ denote the probability (per unit time) that a skilled worker is detected shirking, in which case he is fired and must seek employment as an unskilled worker in the informal sector. The level of effort provided by skilled workers is positive (when employed and not shirking) or zero (when shirking while employed, or when working in the informal sector). The optimal effort level of a skilled worker is determined so that the expected utility derived from working is at least equal to the expected utility of shirking:

$$
\gamma \ln \omega_{S}+(1-\gamma) \ln (1-e) \geq \gamma \pi \ln \omega_{U}+(1-\pi) \gamma \ln \omega_{S}
$$

where $\omega_{S}=w_{S} / \bar{E}$ denotes the real product wage of skilled workers in the formal sector, $\omega_{U}=w_{U} / \bar{E}$ the real wage (measured in terms of traded goods) paid to unskilled workers in the informal sector, and $w_{S}$

${ }^{8}$ The quantity 1 -e could be viewed here as measuring leasure, although the supply of hours is assumed fixed for both categories of
workers (see below). 
(respectively $w_{U}$ ) the nominal wage in the formal (respectively informal) sector. The left-hand side in expression (2) measures the expected utility derived by a skilled worker who is not shirking and provides a level of effort equal to $e$, while the right-hand side measures the expected utility of a shirking worker as a weighted average of the wage earned if caught shirking and fired (with probability $\pi$ ), and if not caught (with probability $1-\pi$ ). In which case the level of effort is zero.

The level of effort demanded by firms is assumed to be such that skilled workers are indifferent between shirking and not shirking--in which case workers choose not to shirk--so that condition (2) holds with equality. Solving for the required level of effort ylelds

$$
e-1-\left(\frac{\omega_{U}}{\omega_{S}}\right)^{\alpha}, \quad \alpha=\frac{\gamma \pi}{1-\gamma}>0
$$

Equation (3) shows that the level of effort produced by skilled workers depends positively on the real wage in the formal sector and negatively on the real wage in the informal sector, which measures the opportunity cost of effort. It can readily be established that the marginal effect of an increase in the real wage in the formal sector on effort is positive but decreasing, and that an increase in the probabilibty of getting caught shirking raises the level of effort.

The representative producer in the formal sector maximizes its

Oour formalization of the decision process that workers face shares some common features with the well-known shirking model of Shapiro and Stiglitz (1984). It differs, however, in two crucial aspects. First, the choice of an effort level in our framework is continuous, while it is a discrete one in the Shapiro-Stiglitz model. Second, in our framework it is only the current market conditions that matter while in the Shapiro-Stiglitz framework workers form their decisions on the basis of the expected discounted utility stream associated with alternative options. We have provided in a different context (Agénor and Aizenman, 1994) an extension of the ShapiroStiglitz model to the labor market setup considered here. 
real profits, that is, using equations (1) and ( 3 ) and assuming that firms incur no hiring or firing costs:

$$
\omega_{S}, L_{S}, L_{F U} \Pi_{F}-Q_{F}\left\{L_{S}\left(1-\left(\frac{\omega_{U}}{\omega_{S}}\right)^{a}\right), L_{F U}\right\}-\omega_{S} L_{S}-\omega_{U}^{\star} L_{F U},
$$

where $\omega_{U}^{*}$ denotes the legally-set minimum real wage (measured in terms of traded goods) for unskilled workers, which is assumed binding in the formal sector. The first-order conditions for this optimization problem are: ${ }^{10}$

$$
\begin{aligned}
& \left(\frac{\partial Q_{F}}{\partial L_{S}}\right)\left[1-\left(\frac{\omega_{U}}{\omega_{S}}\right)^{\alpha}\right]-\omega_{S}, \\
& \left(\frac{\partial Q_{F}}{\partial L_{S}}\right)\left(\frac{\omega_{U}}{\omega_{S}}\right)^{\alpha}-\alpha^{-1} L_{S}, \\
& \partial Q_{F} / \partial L_{F U}-\omega_{U}^{\star} .
\end{aligned}
$$

Optimality conditions ( $4 a$ ) and ( $4 b$ ) can be solved to yield:

$$
\omega_{S}-a \omega_{U}, \quad \sigma=(1+\alpha)^{1 / \alpha}>1
$$

which indicates that, in equilibrium, formal-sector firms always set the efficiency wage for skilled workers at a higher level than the opportunity cost of effort. A graphical determination of the efficiency wage is shown in Figure $1 .^{11}$ Note that skilled workers'

${ }^{10}$ Equations (4) yield the standard Solow condition, which indicates that in equilibrium the elasticity of effort with respect to the product wage must be equal to unity. See Weiss (1990).

${ }^{11}$ If we had assumed that skilled workers provide a minimum level of effort $e_{m}$ when shirking while employed in the formal sector or when hired in the informal sector, the term $(1-\gamma)$ lne ${ }_{m}$ would have appeared on the right-hand side of equation (2) and the level of effort that 
equilibrium wage depends only on the going wage in the informal sector, and not on the minimum wage for unskilled workers in the formal sector. This is because the only employment opportunity avallable to a skilled worker who loses his job in the formal sector as a result of inadequate performance is to join the informal sector labor force.

Equations (3) and (5) imply that in equilibrium effort is constant at $\bar{e}-1-\sigma^{-\alpha}-\alpha /(1+\alpha)$. Substituting the optimal value of $\omega_{S}$ from equation (5) in equation (4a), and solving the resulting equation together with (4c) determines the equilibrium effort level and the demand for skilled and unskilled labor in the formal sector:

$$
L_{S}^{d}=L_{S}^{d}\left(\bar{\omega}_{U}, \omega_{U}^{\star}\right), \quad L_{F U}^{d}=L_{F U}^{d}\left(\bar{\omega}_{U}, \bar{\omega}_{U}^{\star}\right)
$$

An increase in the market-clearing wage for unskilled workers reduces the demand for skilled labor but has an ambiguous effect on the demand for unskilled labor in the formal sector. A rise in the real wage in the informal sector increases in the same proportion as the efficiency wage paid to skilled workers in the formal sector, thus maintaining effort constant. The resulting increase in labor costs lowers the demand for skilled workers. An increase in the minimum wage reduces the demand for unskilled workers but has an ambiguous effect on the demand for skilled workers. As shown in Appendix I, a sufficient condition for both ambigulties to disappear is that the elasticity of substitution between skilled and unskilled labor in the production of traded goods should not too large--a fairly plausible assumption in practice.

Substituting (5) and (6) in (1) yields

$$
Q_{F}^{s}=\mathbf{Q}_{F}\left(\bar{\omega}_{U}, \bar{\omega}_{U}^{*}\right)
$$

would obtain when the wage ratio is unity would be $e_{m}$ instead of 0 . 
which Indicates that, given the condition discussed above, the partial equilibrium effect of an increase in either the minimum wage for unskilled workers or the market-clearing wage in the informal sector on output of traded goods is unambiguously negative.

Production in the informal sector is subject to decreasing returns to unskilled labor and is written as

$$
Q_{I}-Q_{I}\left(L_{I U}\right), \quad Q_{I}^{\prime}>0, \quad Q_{I}^{\prime}<0
$$

while real profits (in terms of traded goods) are given by

$$
\Pi_{I}-z^{-1} Q_{I}\left(L_{I U}\right)-\omega_{U} L_{I U}
$$

where $L_{I U}$ denotes employment of unskilled workers in the informal sector, $z-\bar{E} / P_{I}$ the real exchange rate, and $P_{I}$ the price of the nontraded good produced in the informal sector. Profit maximization yields the familiar equality between marginal revenue and marginal cost, $\omega_{U}=z^{-1} Q_{I}^{\prime}$, from which labor demand can be derived as

$$
L_{I U}^{d}=Q_{U}^{-1}\left(z \omega_{U}\right)=L_{I U}^{d}\left(z \omega_{U}\right), \quad L_{I U}^{d}<0
$$

where $z \omega_{U}$ measures the real product wage in the informal sector. Substituting this result in (8) implies

$$
Q_{I}^{s}-Q_{I}\left(z \omega_{U}\right) . \quad Q_{I}<0
$$

From equations (7) and (11), real factor income--measured in terms of traded goods--is given by

$$
q=z^{-1} Q_{I}\left(z \omega_{U}\right)+Q_{F}\left(\omega_{U}, \omega_{U}^{*}\right)
$$

Let $\bar{L}$ denote total labor supply in the economy, and $\bar{L}_{S}$ the pool of skilled workers. The pool of unskilled workers is thus given by 
$\vec{L}_{U}=\bar{L}-\bar{L}_{S}$. As indicated above, firms in the formal sector determine the real efficiency wage of skilled workers and make their employment decisions first, hiring randomly from the existing work force until their optimal demand for labor is satisfled. Skilled workers who are unable to obtain employment in the formal sector become suppliers in the secondary market and, together with demand there, determine the wage that equilibrates the market for unskilled labor. Formally, the equilibrium condition of the unskilled labor market is given by

$$
\bar{L}_{S}-L_{S}^{d}\left(\omega_{U}, \omega_{U}^{\star}\right)+\bar{L}_{U}-L_{F U}^{d}\left(\omega_{U}, \omega_{U}^{\star}\right)-L_{I U}^{d}\left(z \omega_{U}\right)
$$

which can be solved for the equilibrium value of $\omega_{U}$ :

$$
\omega_{U}=\omega_{U}\left(\overline{z,} \bar{\omega}_{U}^{\star}\right)
$$

Equation (14) shows that the market-clearing wage for unskilled workers is inversely related to the legal minimum wage and the real exchange rate. An increase in the minimum wage lowers the demand for both categories of workers in the formal sector and increases the supply of labor in the informal sector, exerting a downward pressure on real wages there. A real exchange rate depreciation dampens the demand for unskilled workers in the informal sector, requiring a fall in the real wage (measured in terms of traded goods) to maintain equilibrium of the unskilled labor market.

\section{Consumption and asset accumulation}

Households supply labor in quantity $\bar{L}$ and consume traded and nontraded goods produced by the formal and informal sectors. The representative household's lifetime discounted utility is given by ${ }^{12}$

${ }^{12}$ For clarity, only the consumption part of households' utility is explicitly specifled in equation (15), since consumption and effort decisions were assumed to be separable. To simplify calculations, the instantaneous utility derived from total consumption is taken to be logarithmic, while consumption itself is assumed to be a Cobb-Douglas 


$$
\int_{0}^{\infty} \ln \left[c_{I}(t)^{\delta} c_{F}(t)^{1-\delta}\right] e^{-\beta t} d t, \quad \beta>0
$$

where $\beta$ denotes the constant rate of time preference, $c_{I}$ consumption of nontraded goods, and $c_{F}$ consumption of traded goods.

Household hold an internationally traded bond, the stock of which $b$ is assumed to evolve over time according to

$$
\dot{b}=\rho b+q-z^{-1} c_{I}-c_{F}-r
$$

where, denotes real lump-sum taxes (measured in terms of traded goods), and $\rho$ the world interest rate. We assume in what follows that households' initial position is one of net indebtedness $\left(b_{0}<0\right)$. The interest rate facing the country considered varies inversely with the economy's total stock of foreign assets and positively with the long-run ratio of informal and formal sector outputs: ${ }^{23}$

$$
\rho=\rho\left(\bar{b}, Q_{I}^{*} / Q_{F}^{\star}\right)
$$

where $Q_{I}^{*}$ and $Q_{F}^{*}$ denote the long-run values of $Q_{I}$ and $Q_{F} \cdot{ }^{14}$

function in the two categories of goods.

${ }^{23}$ See Agénor and Santaella (1993) for a discussion of the first effect. The formulation used here captures the idea that the world interest rate faced by a small country is a function not only of the existing level of debt but also of the potential capacity to repay, which in turn depends on the economy's ability to produce traded goods as opposed to nontraded goods in the long run. See Aizenman (1989b) for a discussion of the role of openness in determining the country-specific interest rate on world markets.

${ }^{14}$ For simplicity, we assume $\rho()$ to be continuously differentiable. More generally, the function could have a "kink" at a critical value of the stock of bonds. We also impose $\rho(0, \ldots)-\beta$, which fixes the real interest rate, for a zero level of net indebtedness, to the rate of time preference. 
Households treat $q, z, \rho$ and $r$ as given and maximize (15) subject to (16) by choosing a sequence $\left|c_{I}, c_{F}, b\right|_{t=0}^{\infty}$. The solution to this program is characterized by the following familiar conditions:

$$
\begin{aligned}
& \delta / c_{F}-\mu, \\
& c_{I}-\delta z c_{F} /(1-\delta), \\
& \dot{\mu}=(\beta-\rho) \mu,
\end{aligned}
$$

In addition to (16) and the transversality condition $\lim _{t \rightarrow \infty}\left(b e^{-\beta t}\right)-0$. $\mu$, the costate variable associated with the asset accumulation equation, measures the shadow value of wealth.

Equation (18a) yields $c_{F}-c_{F}(\mu)$, with $c_{F}^{\prime}<0$. Substituting this result in equation (18b) yields the demand for nontraded goods produced by the informal sector. Using this result together with equation (11), the equilibrium condition for the nontraded goods market is given by

$$
a_{I}\left(z \omega_{U}\right)-\frac{\delta z}{1-\delta} c_{F}(\mu)+\bar{g}_{I}
$$

where $\bar{g}_{I}$ denotes government spending on goods produced in the informal sector of the economy.

To close the model requires specifying the behavior of the government. Public revenue consists of lump-sum taxes on households, and public spending consists only of expenditure on nontraded goods. To ensure solvency, we assume that the government maintains spending on traded and nontraded goods at a constant level in real terms and adjusts lump-sum taxes to balance the budget:

$$
\tau_{t}-\bar{g}_{F}+z^{-1} \bar{g}_{I}
$$


3. Dynamics of fiscal and labor market policies

We now examine the short-and long-run effects of fiscal and labor market policies. To do so, it is convenient to re-write the model in a more compact form. Substituting equation (14) in equation (7) yields

$$
Q_{F}=q_{F}\left({\stackrel{ \pm}{z}, \omega_{U}^{*}}_{U}\right)
$$

A depreclation of the real exchange rate has a positive effect on the supply of traded goods in the formal sector--since it reduces the market-clearing wage for unskilled workers--but the net effect of an increase in the minimum wage is in general ambiguous. On the one hand, it reduces directly the demand for unskilled workers. On the other hand, it reduces the market-clearing wage for unskilled workers in the Informal sector as well as, through the efficiency condition (5), the real efficlency wage for skilled workers, thus raising employment and output. We will determine below the conditions under which the net effect can be unambiguously signed.

Substituting equation (14) in the equilibrium condition of the nontraded goods market (equation 19) yields

$$
{ }_{q_{I}}\left({\underline{z}, \omega_{U}^{*}}^{+}\right)-\frac{\delta z}{1-\delta} c_{F}(\mu)+\bar{g}_{I}
$$

In general, the net effect of a real depreciation on output in the informal sector is ambiguous. On the one hand, a real depreciation raises directly the product wage in the informal sector, thus exerting a negative effect on output. On the other hand, it reduces indirectly the product wage since it leads to a fall in the real wage of unskilled workers in the informal sector, which in turn lowers the real wage of skilled workers--in order to maintain constant the level of effort-.in the formal sector. The resulting increase in the supply of labor in the informal sector exerts a downward pressure 
on the real wage earned by unskilled workers, which may be large enough to dominate the upward direct effect associated with a depreciation of the real exchange rate on the real product wage there. As shown in Appendix I, the direct effect will dominate if as assumed before the elasticity of substitution between skilled and unskilled labor in the production of traded goods is not too large.

Solving equation (19') yields the equilibrium solution for the real exchange rate:

$$
z=z\left(\mu_{i} \bar{g}_{I}, \bar{\omega}_{U}^{*}\right)
$$

Substituting equations (12), (19) and (20) in equation (16) yields

$$
\left.\dot{b}-\rho\left(b, Q_{I}^{*} / Q_{F}^{*}\right) b+q_{F}\left[z\left(\mu ; g_{I}, \omega_{U}^{*}\right), \omega_{U}^{*}\right)\right]-\bar{g}_{F}-c_{F}(\mu) .
$$

which determines the rate of accumulation of traded bonds. Finally, equation (18c) can be re-written as, using (17):

$$
\dot{\mu} / \mu-\beta-\rho\left(b, Q_{I}^{*} / Q_{F}^{\star}\right) .
$$

Equations (23) and (24) determine the behavior of foreign assets and the marginal utility of wealth over time. Given the solution for

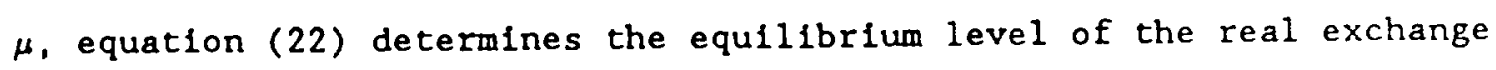
rate.

A linear approximation around the steady state to equations (23) and (24) yields

$$
\left[\begin{array}{l}
\dot{\mu} \\
\dot{b}
\end{array}\right]=\left[\begin{array}{cc}
0 & -\mu^{*}\left(\frac{\partial \rho}{\partial b}\right) \\
\left(\frac{\partial q_{F}}{\partial z}\right)\left(\frac{\partial z}{\partial \mu}\right)-\left(\frac{\partial c F}{\partial \mu}\right) & b^{*}\left(\frac{\partial \rho}{\partial b}\right)+\rho
\end{array}\right]\left[\begin{array}{ll}
\mu-\mu^{*} \\
b-b^{*}
\end{array}\right],
$$

where $\mu^{*}$ and $b^{*}$ denote the steady-state solutions of the system. We 
will assume in what follows that $d(\rho b) / d b>0$, or that the net effect of an increase in the economy's total stock of debt is an increase in interest payments. This assumption follows from the observation that it is generally inefficient for a small country to operate in a region where the supply of credit is backward bending (see Aizenman, 1989a). The system described by (25) is locally saddlepoint stable. ${ }^{\text {is }}$ The steady-state equilibrium is depicted in Figure 2. Curves $[\dot{\mu}-0]$ and $[\dot{b}-0]$ give combinations of $\mu$ and $b$ for which the marginal utility of wealth and the stock of bonds remain constant. The negatively-sloped saddlepath $S S$ leads to the steady-state equilibrium at point $E .^{16}$

Consider a permanent, unanticipated reduction at $t-0$ in government spending on nontraded goods. The dynamics of adjustment are illustrated in Figure 3. A permanent reduction in government spending implies that there is an incipient excess supply of nontraded goods (for a given level of external debt), inducing a real depreciation--a drop in the relative price of the non-traded goods. Furthermore, the long-term openness of the country improves, reducing the interest rate $\rho$ facing the country. For a given marginal utility of wealth there is an incipient current account surplus, which induces a leftward shift in the $[\dot{b}-0]$ curve. The improvement in the creditworthiness of the country implies that the long-run equilibrium calls for higher indebtedness, shifting the $[\dot{\mu}-0]$ curve also leftwards. The new long-run equilibrium obtains at point $E^{\prime}$, with the associated saddlepath denoted $S^{\prime} S^{\prime}$. On impact, both the drop in the interest rate facing the country and the drop in the relative price of non-traded goods increase the consumption of both types of goods, reducing the shadow value of wealth, moving the economy in the

${ }^{15}$ Given our sign assumptions, the determinant of the coefficient matrix in equation (25) is negative. Note that this condition holds irrespective of the value taken by $d(\rho b) / d b$.

${ }^{16}$ The slope of the $[\dot{b}-0]$ curve would be positive if we had assumed that $d(\rho b) / d b<0$. But since the slope of $S S$ does not depend on this derivative, the dynamics of the model would remain qualitatively the same. 
short-run to point $A$. The move from point $E$ to point $A$ is associated with a reduction in the production of nontraded goods, a drop in $\omega_{U}$ (see equation (14)), and a consequent increase in the production of traded goods. However, the increase in consumption of traded goods exceeds the increase in production of the formal sector, and the net effect is a current account deficit. Over time, the external imbalance increases gradually the indebtedness of the country, moving the economy from point $A$ to point $E^{\prime}$. In the transition towards the new long-run equilibrium, the real exchange rate depreciates gradually while consumption of traded goods falls, in order to accommodate the greater deficit in the service account.

Consider now a permanent, unanticipated reduction in the minimum wage for unskilled workers. The drop in the minimum wage affects production in the formal sector via two channels. The direct effect is to increase the demand for unskilled workers in the formal sector, thus increasing production. The indirect effect is a reduction in labor supply in the informal sector, which therefore leads to an increase in the market-clearing wage for unskilled workers. This in turn translates, through the efficiency condition (5), in an upward adjustment in the real wage earned by skilled workers. Thus, while the direct effect increases employment of unskilled workers in the formal sector, the indirect effect works towards a reduction in employment of skilled workers. In Appendix I we derive the sum of these effects, and show that there is a strong presumption that the direct effect will dominate. ${ }^{17}$ Hence, the presence of efficiency wages and segmented labor markets does not alter the neoclassical presumption in the two-sector framework considered here: a reduction in the minimum wage that is enforced only in the formal sector improves the competitiveness of the country, leading to an expansion of the formal sector and a contraction of the informal sector. The

${ }^{17}$ More precisely, we show in Appendix I that the direct effect dominates as long as the share of the informal sector is large, the substitutability between skilled and unskilled workers is not too large, or the formal sector is labor intensive. 
extent to which this result continues to hold under imperfect labor mobility is discussed below.

The "pro-trade bias" associated with the drop in the minimum wage implies that the adjustment path it induces will be qualitatively similar to the transitional dynamics depicted in Figure 3 . The long-run reduction in the relative size of the informal sector improves the creditworthiness of the country, shifting the curve $[\dot{\mu}-0]$ leftwards. Similarly, the incipient excess supply of nontraded goods induces a real depreciation, (that is, an increase in $z)$, shifting thereby the $[\dot{b}-0]$ curve leftwards. Hence, the long-run effects of a reduction in the minimum wage are also qualitatively similar to those induced by a fall in government spending on goods produced in the informal sector: both imply a pro-trade bias.

\section{Taxation and Unemployment Benefits}

In developing countries, taxation affect mostly firms and workers operating in the formal sector--in a similar manner to labor market regulations. While this asymetric feature of tax systems in the developing world may well be the optimal policy response given administrative and othe institutional constraints, it may lead to severe distortions in supply and demand decisions in the short run. In this section, We generalize the framework developed above so as to account for direct income taxation and unemployment benefits for skilled workers in the formal sector, and examine how these modifications affect the determination of sectoral wages, productivity and the composition of employment.

Firms in the formal sector determine as before the optimal levels of employment of both categories of labor as well as skilled workers' wages, without facing a binding quantity constraint in either segment of the labor market. However, instead of assuming that skilled workers who are not hired in the formal sector enter the labor force 
in the informal sector, we now assume that unsuccessful applicants choose to remain unemployed whlle percelving a government-financed unemployment benefit. ${ }^{18}$ The unemployment insurance scheme is financed in part by a tax on wage income, levied at the rate $0<1<1$ on skilled workers employed in the production of traded goods.

Since skilled workers are now faced with a different opportunity cost, the first step in examining the implications of the foregoing assumptions is to determine their optimal level of effort. Suppose for the moment that the unemployment benefit, denoted $\omega_{S}^{*}$, takes the form of a flat real wage. As before, the optimal level of effort is determined so that the expected utility derived from working without shirking be equal in equilibrium to the expected utility derived if caught shirking. Condition (2) becomes now

$$
\gamma \ln \left[(1-\imath) \omega_{S}\right]+(1-\gamma) \ln (1-e) \geq \gamma \pi \ln \omega_{S}^{*}+\gamma(1-\pi) \ln \left[(1-1) \omega_{S}\right]
$$

so that

$$
e-1-\left\{\frac{\omega_{s}^{*}}{(1-\iota) \omega_{s}}\right\}^{\alpha} \text {, }
$$

which Indicates that skilled workers' effort depends negatively on the rate of income taxation and positively on the level of unemployment benefits.

${ }^{18}$ Assuming that only a given proportion of excess supply in the market for skilled workers enters the unskilled labor force would not have any qualitative effect on the analysis. We do not elaborate here on reasons why skilled workers may refuse to work as unskilled labor in the informal economy. Important considerations however are likely to be the loss of social prestige that such a decision may entail, the potentially adverse signaling effect towards future employers, search efficiency (it may be easier to look for a formal-sector job while being unemployed), the perception that human capital may deteriorate rapidly, thus hampering re-entry in the skilled labor force, or that the wage in the informal sector provides less utility than a combination of leisure and unemployment benefit. 
Assuming for simplicity that government transfers consist only of benefit payments to unemployed workers in the formal sector, the government budget constraint (20) becomes

$$
\iota \omega_{S} L_{S}^{d}-\omega_{S}^{*}\left(\bar{L}_{S}-L_{S}^{d}\right)+\bar{g}_{F}+z^{-1} \bar{g}_{I} .
$$

Using equation (27), it is straightforward to verify that in equilibrium the efficiency wage for skilled workers is equal to

$$
\omega_{s}=\sigma \omega_{S}^{*} /(1-\imath),
$$

and that the supply function of the formal sector becomes

$$
Q_{F}-Q_{F}\left\{\frac{\sigma \omega_{S}^{\star}}{(1-\iota)}, \omega_{U}^{\star}\right\},
$$

where both partial derivatives are negative.

The market-clearing wage for unskilled workers now depends indirectly on the efficiency wage for skilled workers (since it affects the demand for unskilled workers in the formal sector) but is independent of the level of employment of skilled workers--since there is no "spillover" effect resulting from a job shortage for that category of labor in the formal economy. The equilibrium condition between supply and demand for unskilled labor is now given by

$$
\bar{L}-\bar{L}_{S}-L_{F U}^{d}\left\{\frac{\omega_{S}^{*}}{(1-\iota)}, \omega_{U}^{\star}\right\}-L_{I U}^{d}\left(z \omega_{U}\right),
$$

which can be solved for $\omega_{U}$.

Using the budget constraint $\left(20^{\prime}\right)$, and equations (29), (30) and the dynamic equations driving the economy, we can now examine the effect of a modification of the income tax rate and unemployment benefits. Given that the level of employment of skilled workers is 
determined by firms in the formal sector, the government budget constraint $\left(20^{\prime}\right)$ establishes a link between the income tax on wages. and the level of unemployment compensation for high-ability workers. As long as the elasticity of the demand for skilled workers (with respect to their own wage) is small relative to the wage premium $\sigma$, higher unemployment compensation requires a higher tax rate for a given level of employment of skilled workers. There exists, thus, an unemployment Laffer curve which, as derived formally in Appendix II and as displayed in Figure 4--drawn for a given level of the real exchange rate-has an inverted $U$-shape in the $\downarrow-\omega_{S}^{\star}$ space. Each wage benefit level is thus supported by two tax rates. We can neglect the higher one, obtaining an "efficient frontier," defined by the leftward portion of the curve. At low levels of the wage benefit, the demand for skilled labor is inelastic, and the efficient frontier is downward sloping: lower unemployment compensation reduces the skilled workers' wage (through the efficiency condition 28) and, for a given tax rate, reduces tax revenue. Hence a higher tax rate is required. As we reach a level of elasticity that is high enough, the curve becomes upward sloping--which corresponds to the stage where lower unemployment compensation reduces the efficiency wage paid to skilled workers, which in turn raises employment by an amount that is large enough to reduce the total revenue needed to support the unemployment compensation scheme.

Assuming that the economy operates on the upward-sloping portion of the efficient frontier of the Laffer curve (between points $A$ and $B$ in Figure 4), a lower level of unemployment compensation raises the level of employment of skilled workers as a result of two complementary effects. First, it reduces directly the efficiency wage by lowering the opportunity cost of skilled workers' effort. Second, it reduces the tax rate on skilled workers-as a result of the government budget constraint--thus reducing the producer real wage (see equation 28 for both effects). The net outcome is a higher level of employment of skilled labor. This generates spillover effects, increasing the demand for unskilled labor, bidding the market-clearing 
wage up and reducing labor absorption in the informal sector. Thus, a lower level of unemployment benefits for skilled workers leads to an expansion of the formal sector and a contraction of the informal economy. The dynamic adjustment process is qualitatively similar to the one depicted in Figure 3.

An alternative formulation of the unemployment benefit scheme is to assume that the level of compensation is set as a function of the minimum wage for unskilled workers and the after-tax going wage for skilled workers:

$$
\omega_{S}^{*}-\omega_{U}^{*}+\theta(1-\imath) \omega_{S} . \quad 0 \leq \theta \leq 1
$$

The relevant condition for deriving the effort function is given by an equation similar to (26). Using (31) to substitute out for $\omega_{S}^{*}$ yields

$$
e-1-\left\{\theta+\frac{\omega_{U}^{*}}{(1-\imath) \omega_{S}}\right\}^{\alpha}
$$

where the level of effort depends now not only on the rate of taxation, but also directly on the unemployment benefit rate $\theta$, as well as the minimum wage for unskilled workers. Solving as before the optimization problem faced by producers in the formal sector yields a relation of the form

$$
(1-\tilde{e})^{1 / \alpha}[\alpha(1-\tilde{e})-\tilde{e}]-\alpha \theta(1-\bar{e})-0
$$

where $\tilde{e}$ denotes the equilibrium level of effort. It can be shown that

$$
\bar{e}-e(\bar{\theta}, \alpha)
$$

which indicates that in equilibrium, effort depends negatively on the unemployment benefit rate and positively on the parameter $\alpha$-and thus, from equation (3), positively on the probability of getting caught shirking-but is independent from the income tax rate (as in the 
previous case) and the minimum wage for unskilled workers.

The efficiency wage for skilled workers in equilibrium is equal to

$$
\omega_{S}=\sigma \omega_{U}^{*}, \quad \sigma=\frac{(1-\iota)^{-1}}{(1-\tilde{e})^{1 / \alpha}-\theta}-\sigma(\hat{\theta}, \iota)
$$

where $\vec{e}$ is given by equation (33). An increase in the unemployment benefit rate or in the income tax rate increase the relative rent captured by skilled workers, measured by the coefficient $\sigma$.

Solving the complete model using equations $\left(20^{\prime}\right),(33)$ and (34), we can now analyze the effect of a modification of the unemployment benefit rate, $\theta .^{1 \theta}$ Suppose that we operate along the "correct" portion of the unemployment Laffer curve, Implying that a drop in $\theta$ calls for a lower income tax rate. Applying (33) and (34) it follows that a drop in the unemployment benefit rate will reduce the efficiency coefficient $\sigma$ as a result of both a lower opportunity wage and a lower income tax rate, and will increase the equilibrium level of effort. Applying the equilibrium conditions determining employment in the formal economy, it can be shown that output expands in the formal sector and contracts in the informal sector, at a rate proportional to the difference between the increase in effort and the fall in skilled workers' wage. ${ }^{20}$ While the mechanism through which these results obtain are qualitatively simflar to those discussed in the first part of this section, there is an additional channel in the present case that reinforces the expansion of the formal sector: the resulting increase in equilibrium effort.

${ }^{19}$ The effects of a change in the income tax rate are qualitatively similar to those discussed previously.

${ }^{20}$ If the production function in the formal sector is given by equation (AI) in Appendix $I$, it can readily be shown that

$$
\hat{Q}_{F}=\frac{\gamma}{1-\gamma} \theta_{S}(\hat{e}-\hat{\sigma}), \quad \hat{Q}_{U}=\frac{\gamma-\epsilon}{(1-\epsilon)(1-\gamma)}{ }_{S}(\hat{e}-\hat{\sigma}),
$$

where $0<\theta_{S}, \theta_{U}<1$ are defined in Appendix I. 


\section{Labor Mobility, Sectoral Wages, and Unemployment}

In the foregoing analysis, unskilled workers that were not hired in the formal sector were able to join immediately the labor force in the informal sector. By assuming that new entrants were successfully bidding wages down, we obviated the possibility that involuntary unemployment of that category of labor could emerge in equilibrium. However, assuming perfect mobility across sectors may lack realism, particularly in a short-run context. Workers typically incur a variety of costs (such as relocation expenses or congestion costs) that may prevent instant reallocation of the labor force. In this section we consider the case where movements of unskilled labor across sectors take place gradually, rather than instantaneously. We also maintain the assumptions made in section II regarding the effort decision of skilled workers and continue to take the composition of the labor force as given. In this extended framework, unemployment of both categories of labor may emerge in the long run.

As in the harris-Todaro approach, potential migrants consider alternative opportunities avallable to them in both sectors and compare their expected utility in each location in order to choose the option that maximizes their expected net utility gains. Suppose that unskilled workers can only allocate time, not the level of effort. ${ }^{21}$ Formally, let $t_{U}$ denote total work time that an unskilled worker is required to commit (in a lump-sum fashion), and $\bar{t} \geq t_{U}$ the maximum amount of leisure that he can possibly enjoy. Assuming as before that consumption and labor supply decisions are separable, and that the instantaneous utility of unskilled workers depends only on leisure and the wage percieved, we have

${ }^{21}$ This assumption is consistent with the observation made above that firms in the informal sector can readily monitor the level of effort provided by their workers. Without loss of generality, we normalize the constant level of effort to zero. 


$$
\ln u\left(\omega, t_{U}\right)-\gamma \ln \omega+\operatorname{aln}\left(\bar{t}-t_{U}\right), \quad \quad a>0
$$

where $\omega$ is the real wage earned by the worker, which depends on the sector of employment.

Abstracting from migration and other relocation costs, the expected utility derived from working in the formal sector consists of two components. The first component is the utility derived from being employed in the formal sector at the legal minimum wage, weighted by the probability of being hired in that sector. This component obtains by replacing $\omega$ in (35) by $\omega_{U}^{*}$ and multiplying the resulting expression--assuming that hiring is random--by the number of unskilled workers actually employed in the formal economy over the number of unskilled workers seeking jobs in the formal sector, $L_{F U}^{d} / L_{F U}^{s} \cdot{ }^{22}$ The second component is related to the possibllity of being registered as unemployed in the formal sector and earning unemployment benefits--without allocating working time--which is taken to represent a fraction $0<\theta_{U}<1$ of the minimun wage. ${ }^{23}$ The expected utility in this case obtains by replacing $\omega$ in (35) by $\theta_{U} \omega_{U}^{*}$ and setting $t_{U}-0$, and multiplying the resulting expression by the proportion of unemployed unskilled workers in the total pool of unskilled workers seeking jobs in the formal economy--that is, the probability of being unemployed in the formal sector. Thus, expected utility conditional on migrating to the formal sector $E\left(\left.u\right|_{F}\right)$ is given by

$E\left(\left.u\right|_{F}\right)-\left\{\gamma \ln \omega_{U}^{*}+\sin \left(\bar{\tau}-t_{U}\right)\right\}\left(\frac{L_{F U}^{d}}{L_{F U}^{s}}\right)+\left\{\gamma \ln \theta_{U} \omega_{U}^{*}+\operatorname{aln}(\bar{t})\right\}\left(\frac{L_{F U}^{s}-L_{F U}^{d}}{L_{F U}^{s}}\right)$.

${ }^{22}$ The absence of a forward-looking ccmponent in wage expectations formed by unskilled workers may be justified by the existence of large costs associated with search, and by the lack of sophistication of the unskilled labor force.

${ }^{23}$ Note that the reason why the choice between being employed or unemployed in the formal sector is not trivial is because unskilled workers must supply labor in a lump-sum fashion. Put differently, $t_{U}$ is not a decision variable. 
By contrast, expected utility derived from working in the informal sector obtains simply by replacing $\omega$ in equation (35) by the market-clearing wage $\omega_{U}$, since the probability of being employed there is unity:

$$
E\left(\left.u\right|_{I}\right)=\gamma \ln \omega_{U}+a \ln \left(\bar{t}-t_{U}\right)
$$

The evolution over time of the unskilled labor force in the formal sector is thus given by

$$
\dot{L}_{F U}^{s}-\kappa\left[E\left(\left.u\right|_{F}\right)-E\left(\left.u\right|_{I}\right)\right], \quad \kappa>0
$$

where $x$ denotes the speed of adjustment. Straightforward manipulations of the above equations yields

$$
\dot{L}_{F U}^{s}=\kappa\left\{\gamma \ln \left(\frac{\omega_{U}^{*}}{\omega_{U}}\right)+\chi_{F}\left[\gamma \ln \theta_{U}+a \ln \left(\frac{\bar{t}}{\bar{t}-t_{U}}\right)\right]\right\},
$$

where $x_{F}=\left(L_{F U}^{s}-L_{F U}^{d}\right) / L_{F U}^{s}$ denotes the unemployment rate of unskilled workers in the formal sector. In the long run, with $\dot{L}_{F U}^{s}=0$, equation (36) yields

$$
\left.\bar{x}_{F}=\frac{\gamma \ln \left(\omega_{U}^{*} / \omega_{U}\right)}{a \ln \left(\left(\bar{t}-t_{U}\right) / \bar{t}\right)-\gamma \ln \theta_{U}}-\bar{x}_{F}{ }^{+} \omega_{U}^{*}, \omega_{U} ; \theta_{U}\right),
$$

which indicates that an increase in the unemployment benefit rate or the minimum wage raises the unemployment rate of unskilled workers in the formal sector. By contrast, an increase in the market-clearing wage in the informal sector lowers the unemployment rate. This is because it reduces the efficiency wage paid to skilled workers, raises labor demand and output in the formal sector and thus employment of unskilled labor.

To obtain the overall unemployment rate for unskilled workers, 
note first that the distribution of the labor force of unskilled labor is given by

$$
\bar{L}_{U}-L_{I U}^{d}+L_{F U}^{d}+\left(L_{F U}^{s}-L_{F U}^{d}\right)
$$

which, given the definition of $x_{F}$, is also equal to

$$
\bar{L}_{U}-L_{I U}^{d}+L_{F U}^{d} /\left(1-x_{F}\right)
$$

The overall unemployment rate of unskilled workers, defined as $x=\left(\bar{L}_{U}-L_{F U}^{d}\right) / \bar{L}_{U}$, is thus given by

$$
x=\frac{x_{F}}{1-x_{F}}\left(L_{F U}^{d} \bar{L}_{U}\right)
$$

so that in the steady state

$$
\begin{gathered}
- \pm \\
\bar{x}-x\left(\omega_{U}, \omega_{U}^{\star}\right)
\end{gathered}
$$

Equation (38) indicates that in the steady state, an increase in the minimum wage has an ambiguous effect on the overall unemployment rate of unskilled workers. A rise in the market-clearing wage (induced, for instance, by an increase in governemnt spending on goods produced in the informal sector, $g_{I}$ ) reduces overall unemployment of unskilled labor.

The aggregate unemployment rate is given by

$$
x_{t o t}=\left(\frac{\bar{L}_{S}-L_{S}^{d}}{\bar{L}}\right)+\left(\frac{L_{F U}^{s}-L_{F U}^{d}}{\bar{L}}\right)
$$

or equivalently: 


$$
x_{\text {tot }}-\left(\frac{\bar{L}_{S}-L_{S}^{d}}{\bar{L}_{S}}\right) n_{S}+x\left(1-n_{S}\right)
$$

where $0<n_{S}<1$ denotes the constant proportion of skilled workers in the labor force.

Given the dynamic equation (36), the extended framework described above can also be used to examine the short-run effects of fiscal and labor market policies unemployment. By rewriting appropriately the government budget constraint $(20)^{24}$ and condensing the model ylelds now a differential equation system in three variables: the marginal utility of wealth, the stock of traded bonds, and the size of the labor force comprised of unskilled workers in the formal sector. Although we omit mathenatical detalls here, it is intuitively clear that the impact effect of a change in the fiscal and labor market policy instruments discussed in previous sections will not alter the qualitative features highlighted before. ${ }^{25}$ In particular, the net effect of a reduction in government spending on aggregate output and the unemployment rate is 11 kely to be ambiguous on impact.

An important implication of the foregoing analysis, thus, is that there may be no close relationship between changes in output and the unemployment rate--that is, no stable Okun's law--as a result of spillover effects between the formal and informal segments of the urban labor market. In periods of adverse macroeconomic shocks

${ }^{24}$ For Instance, if government transfers consist of unemployment benefits paid only to unskilled workers in the formal sector, and if skilled workers continue to be subject to a tax on wages at the rate 6 , the government budget constraint (20) would become

$$
\imath \omega_{S} L_{S}^{d}-\theta_{U} \omega_{U}^{\star}\left(L_{F U}-L_{F U}^{d}\right)+z^{-1} g_{I} .
$$

${ }^{25}$ This results, of course, from the fact that the proportion of the unskilled labor force seeking employment in the formal sector cannot change on impact. The transitional dynamics will in any case differ, as shown by Agénor and Santaella (1993) in a somewhat similar context. 
(resulting, for instance, from cuts in government expenditure), skilled and unskilled workers laid off in the formal sector may seek employment in the informal sector, exerting downward pressure on wages there. Although the wage efficiency effect is likely to dampen the initial reduction in the work force of the formal sector, the sectoral reallocation of labor--which may be particularly marked in the absence of unemployment benefits in the formal sector and non-prohibitive relocation costs--may lead to large shifts in the composition of employment, with little effect on the aggregate unemployment rate. To the extent that labor productivity is lower in the informal sector, negative shocks to output will lead to a fall in average productivity rather than as a rise in open unemployment.

The available evidence suggests indeed that spillover effects of the type described above may have played a significant role in the recent behavior of labor markets in developing countries. Figure 5 displays the behavior of output and the open unemployment rate over time for a group of 12 developing countries during the $1980 \mathrm{~s}$. Although the data must be interpreted with care, ${ }^{26}$ they seem to indicate the absence of a stable relation between the rate of output growth and unemployment. The more detalled evidence examined by Horton et al. (1991), Riveros (1990) and Turnham (1993) also suggests the occurence of large shifts in the composition of employment from the formal to the informal sector in several countries in Latin America, as well as in several other nations of Africa and Asia, particularly during the recessionary years of the $1980 \mathrm{~s} .{ }^{27}$

${ }^{26}$ Published measures of unemployment mostly include only unemployed workers looking for jobs in the formal sector, but not underemployed workers in the informal and rural sectors. The effective degree of labor market slack may thus be understated.

${ }^{27}$ Percelved constraints on the level of employment in the formal sector may also discourage job seeking and lead some workers to simply drop out (at least temporarily) of the labor force, following adverse movements in output. Conversely, positive output shocks may lead to large inflows into the labor force. This "discouraged worker" effect, which is not captured in our framework, may also play a role in explaining the low correlation between output and the unemployment 


\section{Summary and conclusions}

The purpose of this paper has been to examine the implications of fiscal and labor market policies on output, wages and unemployment in a general equilibrium model of a small open developing economy with a large informal sector, a heterogeneous work force, and segmented labor markets. The production structure that we considered assumes that while production in the formal sector consists of traded goods and uses skilled and unskilled labor, output in the informal sector consists of nontraded goods produced using only unskilled labor. Firms in the formal sector were assumed to set the wage rate for skilled labor so as to minimize labor costs per efficiency unit. Skilled workers' effort was shown to depend positively on their wage relative to the wage paid in the informal sector. Unskilled workers employed in the formal sector were assumed to earn a legally-fixed minimum wage, while wages of unskilled workers hired in the informal sector were taken to be fully flexible. In equilibrium, as a result of efficiency considerations, a noncompetitive wage differential emerges across skill categories. The efficiency wage for skilled workers, however, does not depend directly on the minimum wage.

Under the assumption of perfect labor mobility across sectors, we showed that a permanent, unanticipated reduction in government spending on nontraded goods leads in the long run to a depreciation of the real exchange rate, a fall in the market-clearing wage for unskilled labor, an increase in the production of traded goods, and a lower stock of net foreign assets held by the private sector. A permanent, unanticipated reduction in the minimum wage for unskilled workers was also shown to increase output and the demand for labor in

rate in developing countries. In addition, firms can dampen the effect of output shocks on employment by varying hours of work (through overtime), rather than through adjustment in the workforce. 
the formal sector. Hence, in a two-sector economy in which the minimum wage is enforced only in the formal sector and wages in one segment of the labor market are competitively determined, efficiency wage considerations do not alter the standard neoclassical presumption: a reduction in the minimum wage improves competitiveness, and expands the formal sector at the expense of the informal sector.

The basic framework was subsequently extended to introduce direct income taxation and unemployment benefits for skilled workers in the formal sector. Assuming first that the unemployment benefit scheme consisted of paying a constant real wage to the unemployed, we showed that the economy faces an unemployment Laffer curve relating the minimum wage and the income tax rate. If the economy operates on the "correct" portion of the Laffer curve, a reduction in the level of unemployment compensation wil raise the level of employment of skilled workers--thus leading to an expansion of the relative size of the formal sector. If, alternatively, the unemployment benefit scheme is assumed to link the level of compensation to the minimum wage for unskilled workers and the after-tax wage for skilled workers, a reduction in the unemployment benefit rate is also likely to lead to an expansion of output, effort and employment in the formal sector-at a rate proportional to the difference between the increase in effort and the fall in the premium associated with skilled workers' wage.

Finally, we considered the case where unskilled workers face a decision to migrate from the informal sector to the formal sector. We derived the incentive structure on the basis of which workers form their decision, along the lines suggested by Harris and Todaro (1970). By focusing the analysis on the long run, we showed that the overall unemployment rate of unskilled workers varies inversely with the market-clearing wage for unskilled labor, but that a change in the minimum wage for unskilled labor in the formal sector has an ambiguous effect. An important prediction of the model, the absence of a stable relation between output and unemployment in the short run, appeared to be consistent with the avallable evidence for developing countries. 
The analytical framework developed here can be further extended in a variety of directions. One area of investigation would be to consider a situation where there exist technological "input-output" links between the formal and the informal sectors. For instance, the formal sector may be assumed to produce an intermediate good that is used in the production process for informal-sector goods. Complementarity effects of this type are likely to alter substantialiy the effect of macroeconomic shocks on output and the allocation of labor across sectors. Another possibility would be to examine the implications of alternatives to the Harris-Todaro intersectoral migration mechanism, perhaps by introducing the kind of heterogeneitles discussed by Lindbeck and Snower (1991). It may also be useful to explore, in a growth context, the effects of alternative mechanisms that may account for movements over time across skill categories, thus explaining endogenously changes in the composition of the labor force. Skill improvements take place through a variety of institutional forms, such as apprenticeship programs, on-the-job training, and internal labor markets. At the same time, training may impose a cost on firms and thus affect the sensitivity of the demand for labor with respect to changes in current wages. A final issue of importance would be to explain why government impose minimum wage laws in the first place--a phenomenon that creates, in our model, market segmentation for unskilled workers. A political economy approach may provide the critical elements necessary to account for the incentives to restrict wage flexibility. ${ }^{20}$ A sensible point of departure might be the recognition that formal-sector workers may be better organized (through pressure groups, for instance) than informal-sector workers, and may thus have a greater ability to force incumbent policymakers to

${ }^{28} \mathrm{~A}$ different approach is adopted by Drazen (1986), who argues that minimum wage legislation may be welfare-improving--relative to the competitive equilibrium--in a model where information about worker quality is imperfect and labor quality rises with increases in the average market wage, as in urban labor markets in developing countries where entrants are migrants from rural areas. 
legislate in their favor.

Although these extensions may prove valuable in their own right, they are unlikely to alter some of the key results of this paper. In particular, worker heterogeneity and labor market segmentatation (induced by institutional constraints and firms' optimizing behavior) are essential elements in explaining the functioning of urban labor markets in developing countries, and play a key role in the transmission process of macroeconomic and structural policy shocks on output and employment. In a setting where the level of employment is determined by firms, policymakers will typlcally face a tradeoff in using unemployment benefits and direct taxation of income. These results have important implications for.the design of macroeconomic reform programs. 


\section{Appendix I}

The purpose of this Appendix is to examine under what conditions it is possible to sign unambiguously the effect of the minimum wage on the supply of traded goods in the formal sector, and the effect of changes in the real exchange rate on output of the informal sector. To that effect, we assume that output in the formal sector is produced with a Cobb-Douglas technology in capital and a composite labor input, which takes the form of a CES function in skilled and unskilled labor. Assuming that the capital stock is fixed and normalized to unity ylelds :

$$
Q_{F}-\left[\left(e L_{S}\right)^{\epsilon}+L_{F U}^{\epsilon}\right]^{\gamma / \epsilon}, \quad \epsilon \leq 1 \quad 0<\gamma<1
$$

where $y$ measures the share of labor in production and $\epsilon$ a coefficient related to the elasticity of substitution between skilled and unskilled labor, which is equal to $1 /(1-\epsilon)$.

Maximizing profits in the formal sector yields the following first-order conditions for the employment of skilled and unskilled labor:

$$
\begin{aligned}
& \left(L_{F U} / \tilde{e}_{L}\right)^{\epsilon-1}-\tilde{e} \omega_{U}^{*} / \sigma \omega_{U}, \\
& \gamma L_{F U}^{\epsilon-1}\left[\left(\tilde{e}_{S}\right)^{\epsilon}+L_{F U}^{\epsilon}\right]^{(\gamma-\epsilon) / \epsilon}-\omega_{U}^{*},
\end{aligned}
$$

where the result shown in (A2a) uses equation (5). $\bar{e}=\alpha /(1+a)$ denotes the optimal level of effort, which depends only on the parameter $\alpha$.

In percentage change form, equations ( $A 2$ ) yield

$$
\begin{aligned}
& (\epsilon-1) \hat{L}_{F U}+(\boldsymbol{\gamma}-\epsilon)\left(\theta_{S} \hat{L}_{S}+\theta_{U} \hat{L}_{F U}\right)-\hat{\omega}_{U}^{*}, \quad 0<\theta_{S}, \theta_{U}<1 \\
& (\epsilon-1)\left(\hat{L}_{F U}-\hat{L}_{S}\right)-\hat{\omega}_{U}^{*}-\hat{\omega}_{U},
\end{aligned}
$$


where $\theta_{S}-\left(e L_{S}\right)^{\epsilon} /\left[\left(e L_{S}\right)^{\epsilon}+L_{F U}^{\epsilon}\right]$, and $\theta_{U}-1-\theta_{S}$. Solving the above equations yields

$$
\begin{aligned}
& \hat{\Sigma}_{S}=\left[(\epsilon-\gamma) \theta_{U} \hat{\omega}_{U}^{*}-\hat{\omega}_{U}\left(1-\gamma \theta_{U}-\epsilon \theta_{S}\right)\right] /(1-\epsilon)(1-\gamma), \\
& \hat{\Sigma}_{F U}-\left[(\epsilon-\gamma) \theta_{S} \hat{\omega}_{U}-\hat{\omega}_{U}^{*}\left(1-\gamma \theta_{S}-\epsilon \theta_{U}\right)\right] /(1-\epsilon)(1-\gamma) .
\end{aligned}
$$

Since $1-\gamma \theta_{U}-\epsilon \theta_{S}<1, \hat{L}_{S} / \hat{\omega}_{U}<0$ and $\hat{i}_{F U^{\prime}} / \hat{\omega}_{U}^{*}<0$. A sufficient condition for both $\hat{i}_{S} / \hat{\omega}_{U}^{*}$ and $\hat{L}_{F U} / \hat{\omega}_{U}$ to be negative is that $\epsilon<\gamma$, as indicated in the text.

From equations (A1), $\hat{Q}_{F}-\gamma\left(\theta_{S} \hat{L}_{S}+\theta_{U} \hat{L}_{F U}\right)$. Using (A3) yields

$$
\hat{Q}_{F}=-\frac{\boldsymbol{\gamma}}{1-\gamma}\left(\hat{\omega}_{U}{ }^{\theta} S+\hat{\omega}_{U}^{*} \theta_{U}\right)
$$

The production function in the informal sector is given by

$$
Q_{I}=\left(L_{I U}\right)^{\eta}, \quad 0<\eta<1
$$

so that, using equation (10) in the text

$$
\hat{i}_{I U}-\left(\hat{\omega}_{U}+\hat{z}\right) /(1-\eta)
$$

The equilibrium condition of the labor market in the informal sector (equation 13) can also be written as

$$
-(1-\eta)^{-1}\left(\hat{\omega}_{U}+\hat{z}\right) n_{I}+n_{F}\left(n_{F S} \hat{L}_{S}+n_{F U} \hat{L}_{F U}\right)=0 .
$$

where $n_{F}=\left(L_{S}+L_{F U}\right) / \bar{L}$ measures the proportion of the total labor force employed in the formal sector, and $n_{I}-1-n_{F}$. The coefficient $n_{F S}-L_{S} /\left(L_{S}+L_{F U}\right)$ measures the proportion of skilled workers in total employment in the formal sector, and $n_{F U}-1 \cdot n_{F S}$. 
Substituting equations $(A 3)$ and $(A 5)$ in $(A 6)$ yields

$$
\begin{aligned}
& -(1-\eta)^{-1}\left(\hat{\omega}_{U}+\hat{z}\right) n_{I}+\frac{n_{F}}{(1-\epsilon)(1-\gamma)}\left\{\hat{\omega}_{U}\left[\theta_{S}(\epsilon-\gamma) \cdot n_{S}(1-\gamma)\right]\right. \\
& \left.+\hat{\omega}_{U}^{*}\left[\theta_{U}(\epsilon-\gamma)-n_{U}(1-\gamma)\right]\right\}=0 .
\end{aligned}
$$

From (A4), we have

$$
s g\left(\frac{\partial Q_{F}}{\partial \omega_{U}^{*}}\right)-s g\left[\theta_{U}+\theta_{S}\left(\hat{\omega}_{U} / \hat{\omega}_{U}^{*}\right)\right]
$$

Using (A7) yields

$$
\frac{\hat{\omega}_{U}}{\hat{\omega}_{U}^{*}}--\frac{n_{F}\left[\theta_{U}(\gamma-\epsilon)+n_{U}(1-\gamma)\right] / \Omega}{(1-\eta)^{-1} n_{I}+n_{F}\left[\theta_{S}(\gamma-\epsilon)+n_{S}(1-\gamma)\right] / \Omega}
$$

where $\Omega-(1-\epsilon)(1-\gamma)$. Substituting this result in $(A 8)$ yields

$$
s g\left(\frac{\partial Q_{F}}{\partial \omega_{U}^{*}}\right)-s g\left\{\theta_{U}-\frac{\theta_{S} n_{F}\left[\theta_{U}(\gamma-\epsilon)+n_{U}(1-\gamma)\right]}{(1-\eta)^{-1} \Omega_{I}+n_{F}\left[\theta_{S}(\gamma-\epsilon)+n_{S}(1-\gamma)\right]}\right\},
$$

or, after some manipulations,

$$
s g\left(\frac{\partial Q_{F}}{\partial \omega_{U}^{*}}\right)=-s g\left\{\frac{{ }^{n_{I} \theta_{U}(1-\epsilon)}}{1-\eta}+n_{F}\left(\theta_{U}-n_{U}\right)\right\}
$$

The sign of the partial effect of an increase in the minimum wage for unskilled workers on the level of output in the formal sector depends thus on the sign of $\left(\theta_{U}-n_{U}\right)$. Given the definitions above.

$$
\theta_{U}=n_{U}=\frac{L_{F U}^{\epsilon}}{\left(\tilde{e} L_{S}\right)^{\epsilon}+L_{F U}^{\epsilon}} \cdot \frac{L_{F U}}{L_{S}+L_{F U}}
$$


If $\epsilon \rightarrow 0$ (Cobb-Douglas technology), we have, using equation (5) in the text,

$$
s g\left(\theta_{U}-n_{U}\right)-s g\left(L_{S}-L_{F U}\right)-s g\left\{\frac{\omega_{U}^{\star}}{\sigma \omega_{U}}-1\right\}<0
$$

as long as $\omega_{U}^{*}<\sigma \omega_{U}$, that is, as long as the minimum wage for unskllled labor in the formal sector is lower than the efficiency wage earned by skilled workers.

$$
\begin{aligned}
& \text { If } \epsilon \rightarrow-\infty \text { (Leontief technology), we also have } \\
& s g\left(\theta_{U}-s_{U}\right)-s g\left(L_{S}-L_{F U}\right)-s g(1-e)>0 .
\end{aligned}
$$

Thus, in the two particular cases considered above, the sign of the partial effect of an increase in the minimum wage on output in the formal sector differ. ${ }^{29}$ We can also derive, however, a general condition for this result to obtain for $1>\epsilon>-\infty$, that is, the case for which the substitutability between skilled and unskilled workers is not too large. Using equation ( $A 10$ ) yields

$$
s g\left(\theta_{U}-s_{U}\right)=s g\left[L_{S} L_{F U}^{\epsilon}-\left(\tilde{e}_{L}\right)^{\epsilon} L_{F U}\right]-s g\left\{\left(\frac{L_{S}}{L_{F U}}\right) 1-\epsilon-\bar{e}^{\epsilon}\right\}
$$

which, using $(A 2 a)$, yields

$$
s g\left(\theta_{U}-n_{U}\right)-s g\left\{\frac{\omega_{U}^{*} e^{\epsilon}}{\sigma \omega_{U}}-\bar{e}^{-\epsilon}\right\}
$$

${ }^{29}$ Note that if $\epsilon \rightarrow 1$ (the production function is linear and skilled and unskilled labor are perfectly substitutable inputs), firms in the formal sector would never hire skilled workers since in equilibrium $\omega_{S}>\omega_{U}$. 
which is always negative, regardless of the optimal level of effort. Note that a sufficient condition for $s g\left(\partial Q_{F} / \partial \omega_{U}^{*}\right)<0$ is that $n_{I}$ or $y$ be relatively close to unity. Equivalently, the share of the informal sector must be large, or the formal sector must be labor intensive.

Consider now the effect of a real exchange rate depreciation on output of the informal sector. From the production function defined earlier, we have

$$
s g\left(\frac{\partial Q_{I}}{\partial z}\right)--s g\left(1+\hat{\omega}_{U} / \hat{z}\right)
$$

Equation (A7) yields

$$
\frac{\hat{\omega}_{U}}{\hat{z}}--\frac{(1-\eta)^{-1} n_{I}}{(1-\eta)^{-1} n_{I}+n_{F}\left[\theta_{S}(\gamma-\epsilon)+n_{S}(1-\gamma)\right] \AA}
$$

so that

$$
s g\left(\frac{\partial Q_{I}}{\partial z}\right)-\operatorname{sg}\left[\theta_{S}(\gamma-\epsilon)+n_{S}(1-\gamma)\right] .
$$

The quantity in brackets on the right-hand side of equation (A12) is unambiguously positive if $\boldsymbol{\gamma}>\boldsymbol{\epsilon}$. If this condition holds, then $\partial Q_{I} / \partial z<0$, as indicated in the text. 


\section{Appendix II}

This Appendix provides a formal derivation of the slope of the unemployment Laffer curve. From equations $\left(20^{\prime}\right)$ and (28), we have

$$
\omega_{S}^{*}\left\{\left(1+\frac{\iota \sigma}{1-\imath}\right) L_{S}^{d}-\bar{L}_{s}\right\}-g-0
$$

where $g=\bar{g}_{F}+z^{-1} \bar{g}_{I}$. From this equation we infer that

$$
s g\left\{\frac{d \omega_{S}^{*}}{d \iota}\right\}-\operatorname{sg}\left\{\frac{\sigma-(1+\iota \sigma-\iota) \eta_{S}}{g(1-\iota) / \omega_{S}^{*} L_{S}^{d}-\eta_{S}(1+\iota \sigma-\iota)}\right\},
$$

where $\eta_{S}=-d \ln L_{S}^{d} / d \ln \omega_{S}$ denotes the elasticity of the demand for skilled labor. It is readily apparent that if $\eta_{S}$ is low, the curve is downward sloping. From (Al) we have

$$
g(1-6) / \omega_{S}^{*} L_{S}^{d}<\sigma
$$

so that the Laffer curve is upward-sloping if the elasticity of the demand for skilled labor in the formal sector satisfies

$$
g(1-\imath) / \omega_{S}^{*} L_{S}^{d}<\eta_{S}(1+\imath \sigma-\iota)<\sigma \text {, }
$$

and it reaches the highest $\omega_{S}^{*}$ for $\eta_{S}-\sigma /(1+\imath \sigma-\imath)$.

To gain further insight, it is useful to use a linear approximation of the demand for labor function, $L_{S}^{d} \cong 1_{0}-1_{1} \omega_{S}$. Using equation (28) in the text, $L_{S}^{d} \cong 1_{0}-\sigma 1_{1} \omega_{S}^{*} /(1-1)$. Substituting this equation in (Al) yields

$$
\omega_{S}^{*}\left\{\left(1+\frac{\iota \sigma}{1-1}\right)\left(1_{0}-\frac{\sigma l_{1} \omega_{S}^{*}}{1-1}\right)-\bar{L}_{S}\right\}-g=0
$$


which is represented in Figure 4. The efficient frontier is defined by the leftward portion of the ellipsold. Note that one should add the requirement that expected utility of a skilled worker exceed his utility as unskilled. This implies that the lowest portion of the efficient frontier is not attainable.

It is straightforward to show that a reduction in total government spending $g$ leads to a leftward shift of the efficient frontier--thus reducting the tax rate needed to support a given level of unemployment compensation for skilled workers. An increase in the parameter measuring the wage efficiency premium $\sigma$ shifts the efficient frontier downwards, because it implies that a given unemployment compensation and given taxes are associated with higher cost for skilled labor. To compensate for 1t, holding the tax rate given, requires a lower wage benefit. Finally, a reduction in the supply of skilled labor implies that, for a given unemployment benefit, that unemployment is smaller, hence the tax rate required to finance the benefit scheme is lower. The efficient frontier shifts leftwards in this case. 


\section{References}

Agénor, Plerre-Richard, and Joshua Aizenman, "Technological Change, Relative Wages, and Unemployment," unpublished, Internationnal Monetary Fund (March 1994).

Agénor, Plerre-Richard, and Julio A. Santaella, "Efficiency wages and Sectoral Labor Mobility in an Open Economy," Working Paper No 93/79, International Monetary Fund (September 1993).

Aizenman, Joshua, "Country Risk, Incomplete Information and Taxes on International Borrowing," Economic Journal, Vol. 99 (March 1989a), pp. 147-61.

-, "Investment, Openness, and Country Risk," In Analytical Issues in Debt, ed. by Jacob A. Frenkel, Michael P. Dooley, and Peter Wickham, International Monetary Fund (Washington, DC: 1989b).

Carmichael, H. Lorne, "Efficiency Models of Unemployment," Economic Inquiry, Vo1. 28 (April 1990), Pp. 269-95.

Demekas, Dimitri G., "Labor Market Segmentation in a Two-Sector Model of an Open Economy," Staff Papers (International Monetary Fund), Vol. 37 (December 1990), pp. 849-64.

Drazen, Allan, "Optimal Minimum Wage Legislation," Economic Journal, Vo1. 96 (September 1986), PP. 774-84.

Edwards, Sebastian, "Terms of Trade, Tariffs and Labor Market Adjustment in Developing Countries," World Bank Economic Review, Vol. 2 (May 1988), Pp. 165-85.

Harris, John, and Michael P. Todaro, "Migration, Unemployment and Development: A Two-Sector Analysis," American Economic Review, Vo1. 60 (March 1970), PP. 126-43. 
Horton, Susan, Ravi Kanbur, and Dipak Mazumdar, "Labor Markets in an Era of Adfustment," Economic Development Institute, Working Paper No 694, the World Bank (Washington, DC: May 1991).

Lindbeck, Assar, and Dennis J. Snower, "Segmented Labor Markets and Unemployment," Discussion Paper No 523, Centre for Economic Policy Research (April 1991).

Mazumdar, Dipak, "Segmented Labour Markets in LDCs," American Economic Review, Vol. 73 (May 1983), Pp. 254-59.

Riveros, Luls, "Recession, Adjusmtent and the Performance of Urban Labor Markets in Latin America," Canadian Journal of Development Studies, Vol. 11 (March 1990), pp. 34-59.

Rosenzweig, Mark, "Labour Markets in Low-Income Countries," in Hollis Chenery, and T.N. Srinivasan, eds., Handbook of Development Economics, Vol. I, North Holland (Amsterdam: 1988).

Shapiro, Carl, and Joseph E. Stiglitz, "Equilibrium Unemployment as a Worker Discipline Device," American Economic Review, Vol. 74 (June 1984), PP. 433-44.

Taubman, Paul, and Michael L. Wachter, "Segmented Labor Markets," in Handbook of Labor Economics, ed. by Orley Ashenfelter and Richard Layard, North Holland (Amsterdam: 1986).

Turnham, David, Employment and Development: A New Review of Evidence, Development Centre, OECD (Paris: 1993).

Welss, Andrew, Efficiency Wages: Models of Unemployment, Layoffs, and Wage Dispersion, Princeton University Press (Princeton, New jersey: 1990). 
</ref_section> 
Figure 1

Productivity and Wages in the Formal Sector

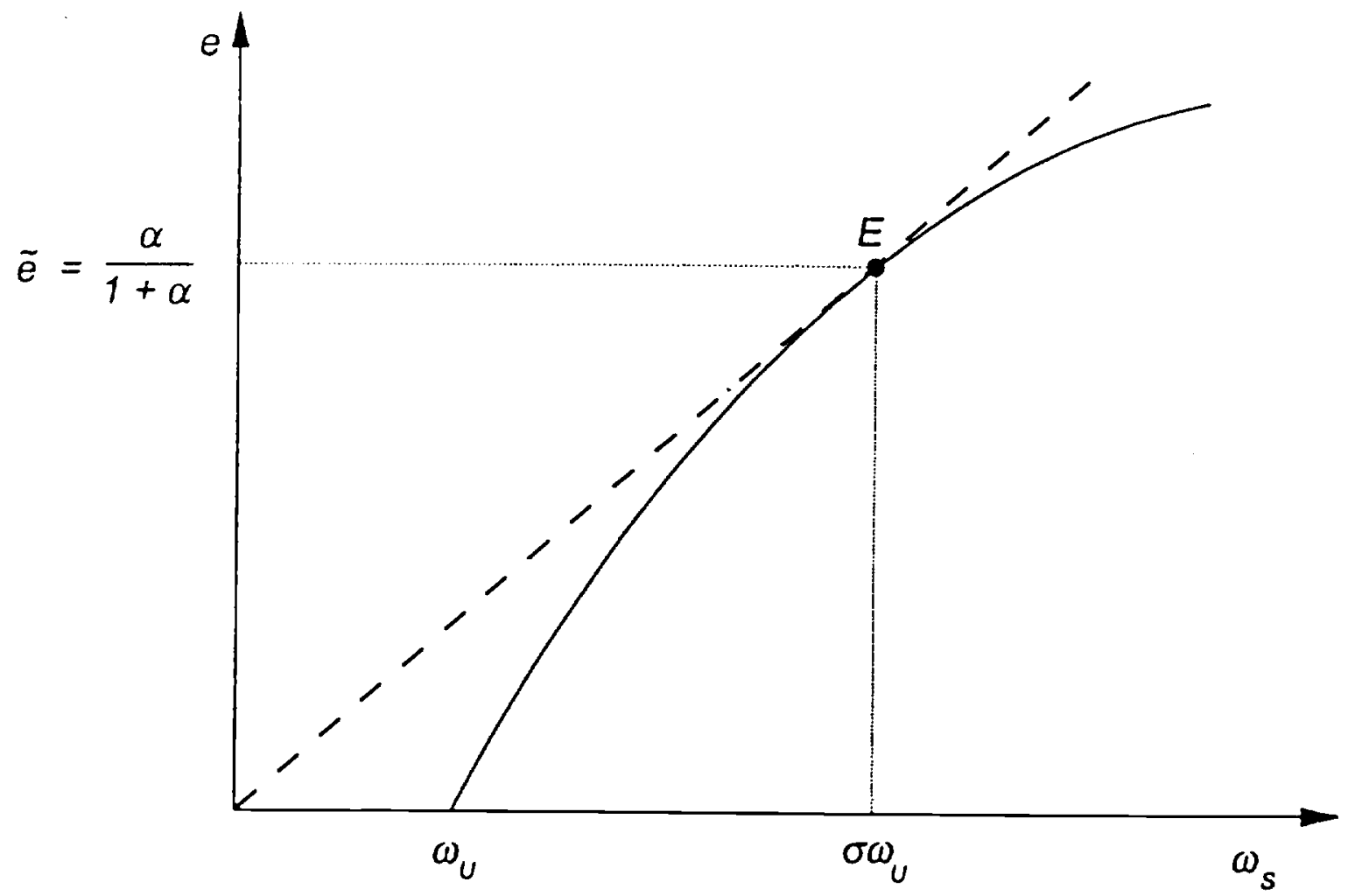


Figure 2

Steady-State Equilibrium

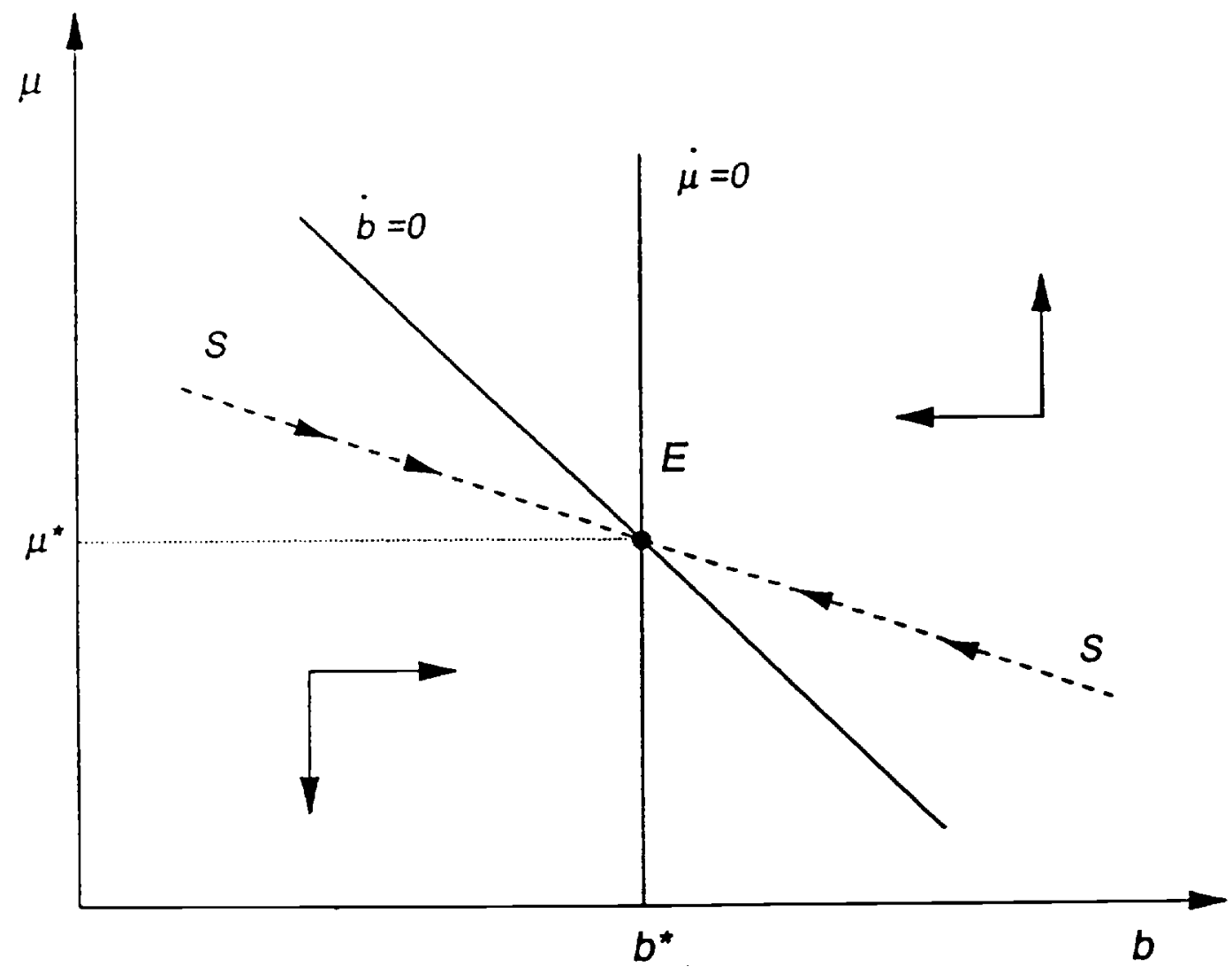


Figure 3

Reduction in Government Spending

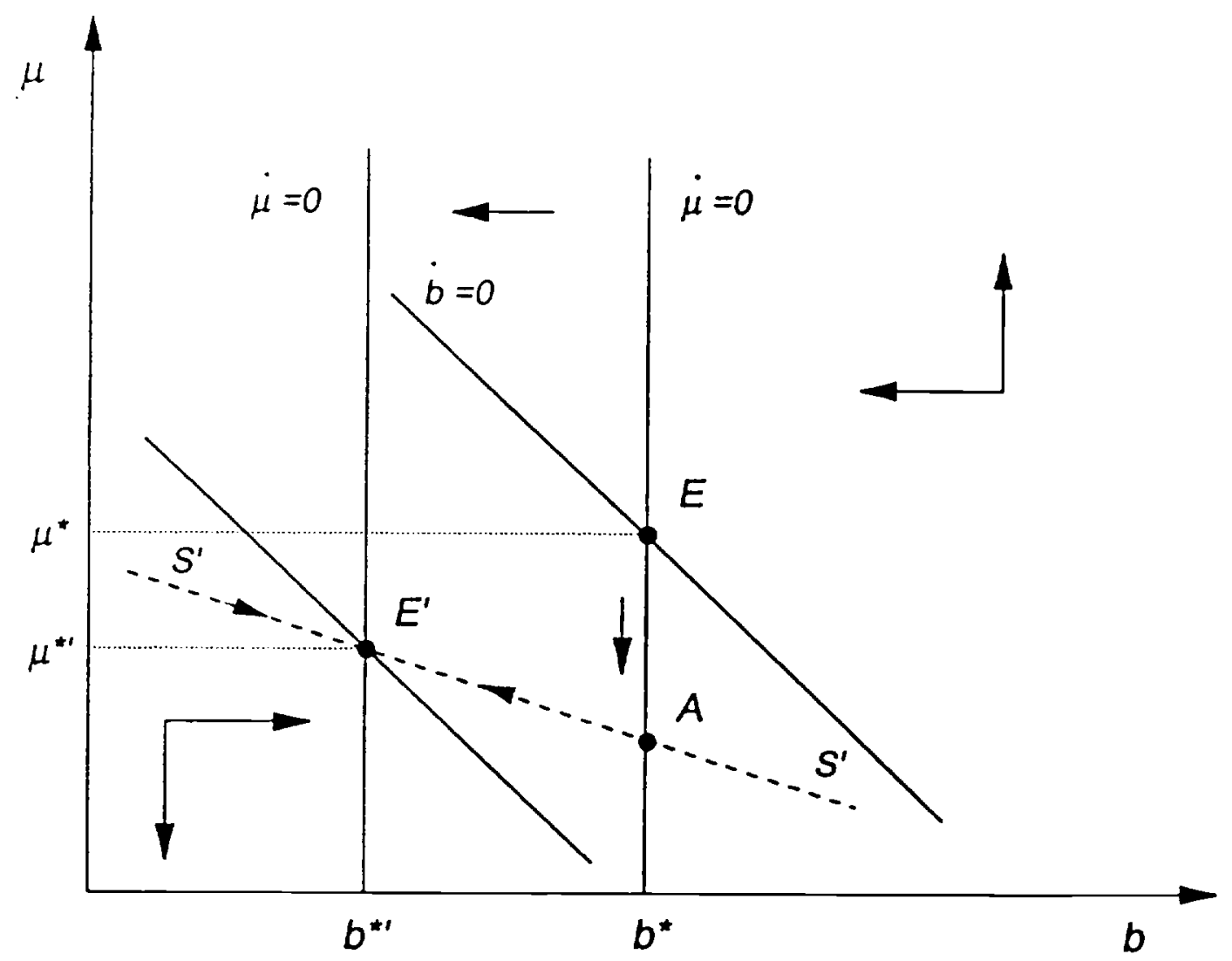


Figure 4

The Unemployment Laffer Curve

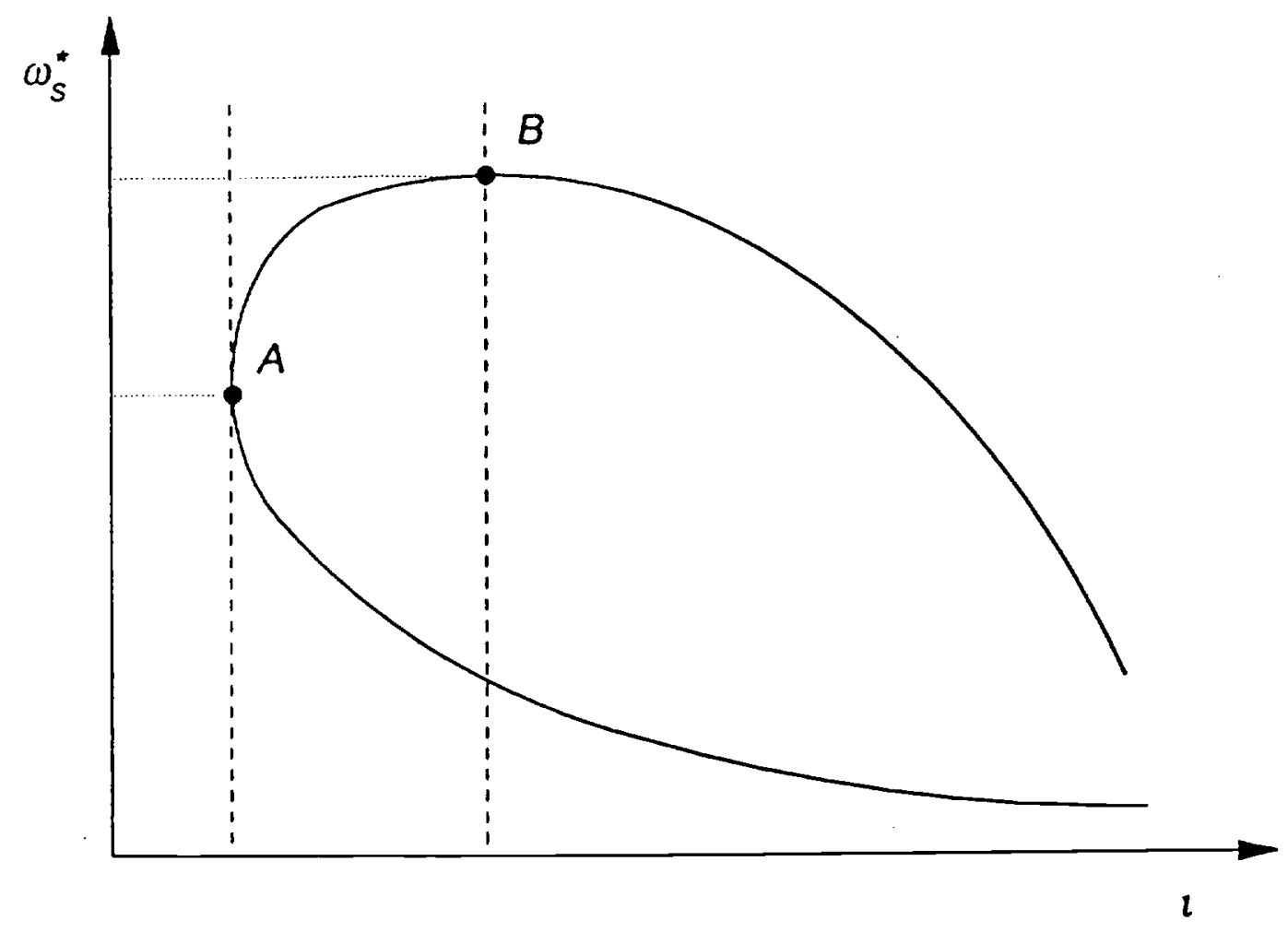


Figure 5

\section{Output and Unemployment in Developing Countries}
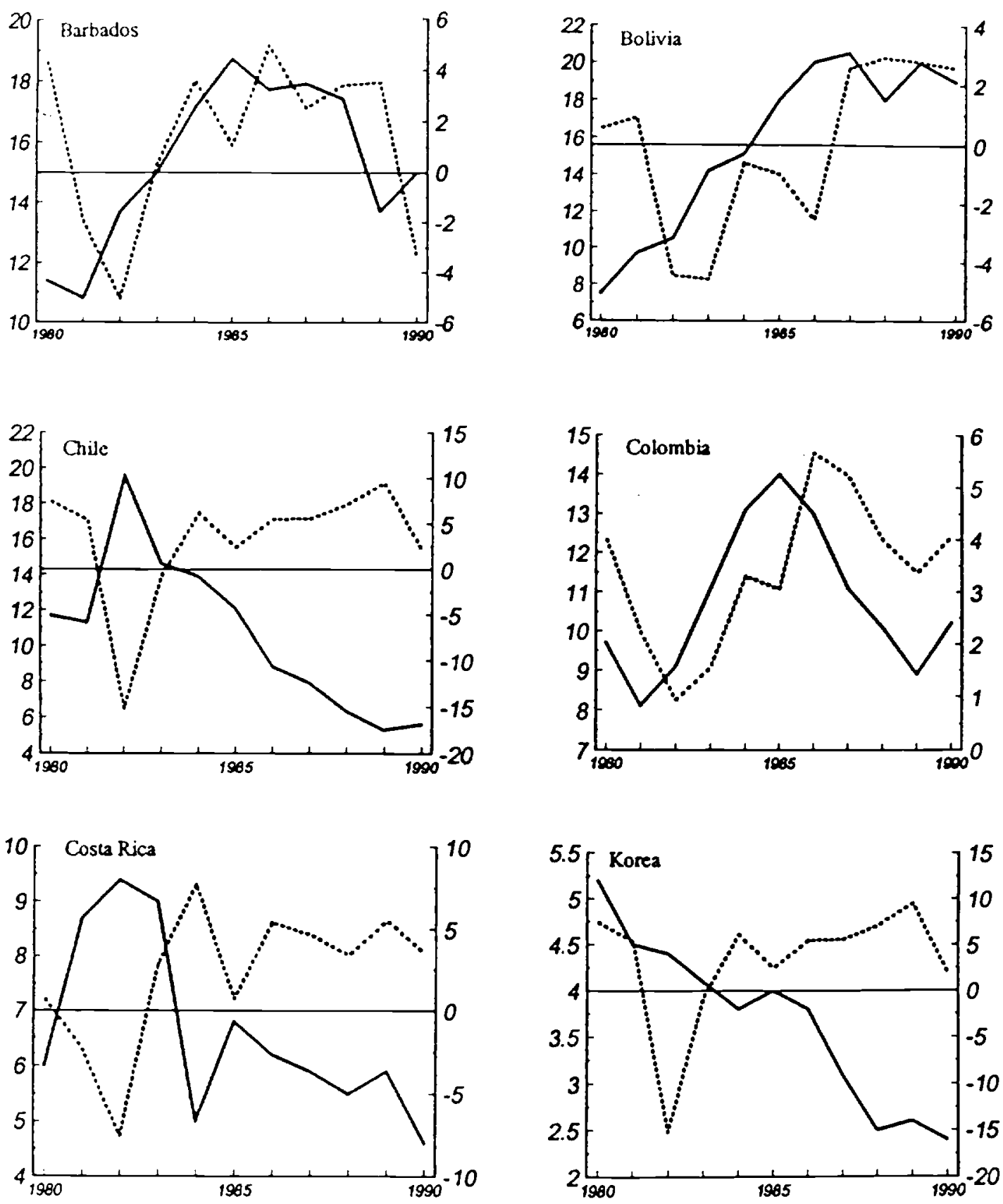

Sources: ILO Yearbook and International Financial statistics. 
Figure 5 (concluded)

Output and Unemployment in Developing Countries

- Uemployment rate, in pereent (left scale)

.... Real GDP growth, in percent (right scale)
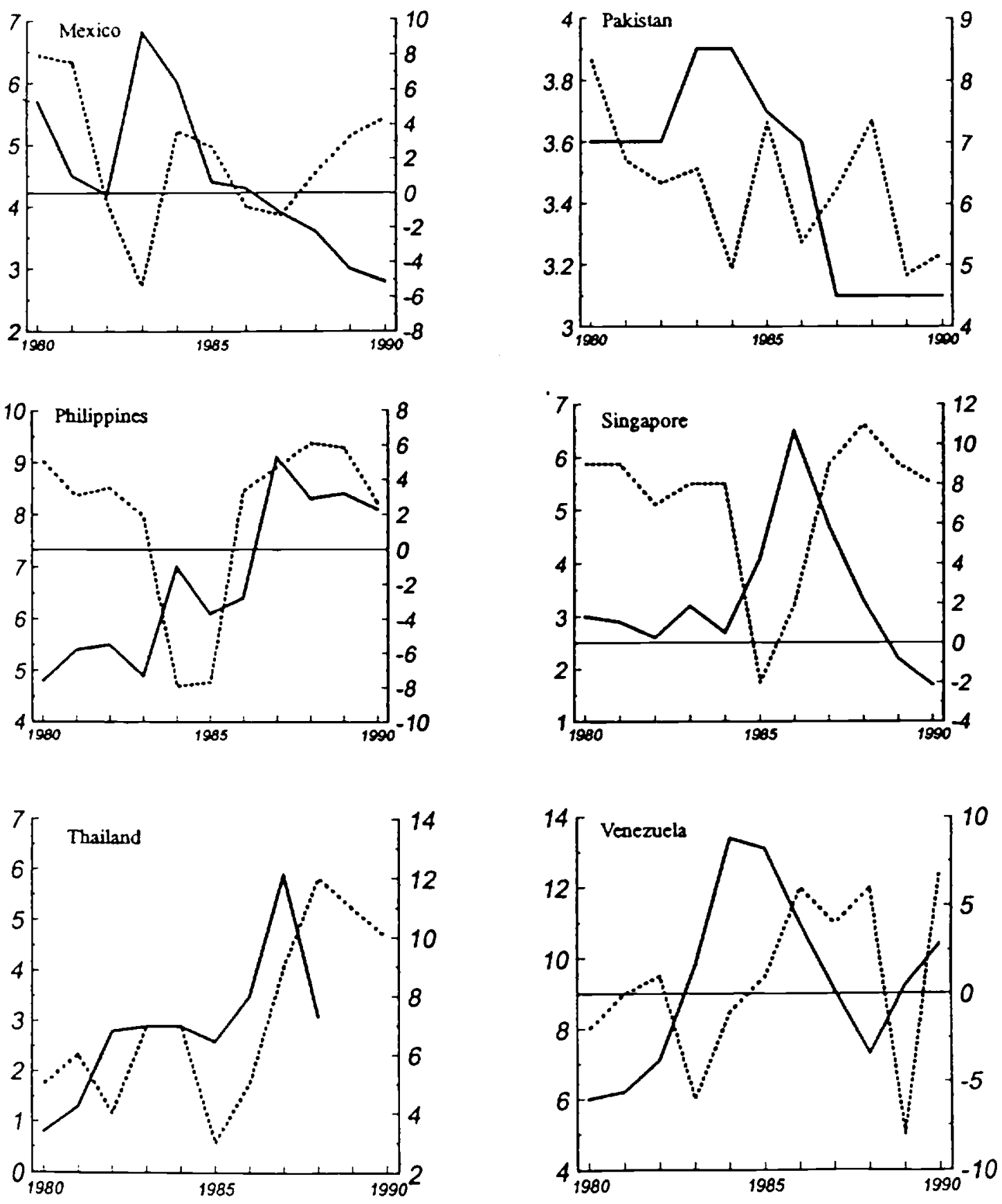

Sources: ILO Yearbook and international Financial statistics. 